\title{
STUDY ON THE RELATIONSHIP BETWEEN MOISTURE CONTENT AND THERMAL CONDUCTIVITY OF $\mathrm{SiO}_{2}$ FIBER MEMBRANE
}

\author{
Liulei $^{1}$, Liu Wei-jun ${ }^{2}$, Ding Xiu-peng ${ }^{3}$ \\ ${ }^{1}$ College of Mechanical Engineering, Shanghai University of Engineering Science \\ ${ }^{2}$ College of Mechanical Engineering, Shanghai University of Engineering Science \\ ${ }^{3}$ College of Mechanical Engineering, Shanghai University of Engineering Science
}

\begin{abstract}
On the basis of testing the $\mathrm{SiO}_{2}$ fiber membrane material, the relationship between the moisture content of the $\mathrm{SiO}_{2}$ fiber membrane and the thermal conductivity is obtained. The results show that the thermal conductivity of $\mathrm{SiO}_{2}$ fiber membrane increases slowly with the increase of moisture content first and then increases rapidly, and then tends to be stable and slow. The thermal conductivity of $\mathrm{SiO}_{2}$ fiber membrane is minimum in the case of almost no water. When the moisture content of $\mathrm{SiO}_{2}$ fiber membrane is higher than $20 \%$, the thermal conductivity increases rapidly with the increase of moisture content, the maximum thermal conductivity occurs when the moisture content of $\mathrm{SiO}_{2}$ fiber membrane is about 46.67\%, the thermal conductivity of $\mathrm{SiO}_{2}$ fiber membrane tends to be stable between $46.67 \%$ and $100 \%$ of its moisture content.
\end{abstract}

Keywords: $\mathrm{SiO}_{2}$ Fiber Membrane; Moisture Content; Thermal Conductivity.

\section{INTRODUCTION}

$\mathrm{SiO}_{2}$ fiber membranehas been frequently applied to thermal insulation materials because of its many advantages[1], such as good thermal stability, low heat transfer coefficient, electrical insulation and excellent optical performance. The heat transfer of the $\mathrm{SiO}_{2}$ fiber membrane during the moisture absorption is a compound heat transfer process, the internal heat transfer mechanism of $\mathrm{SiO}_{2}$ fiber membrane varies with the moisture content of the fiber membrane, when the water content is high, the diffusion and heat transfer of water molecules occurs[2], and there is also the diffusion and heat transfer of the gas. In this paper, the changing rule of thermal conductivity of $\mathrm{SiO}_{2}$ fiber membrane under different conditions is studied through experiments, which provides some basis for the research of $\mathrm{SiO}_{2}$ fiber membrane thermal insulation filling materials.

\section{TEST METHODS AND INSTRUMENTS}

\subsection{Test Methods}

A standard parameter to measure the strength of thermal conductivity is the coefficient of thermal conductivity[3]. According to the relationship between temperature and time, the method of measuring the thermal conductivity of material can be divided into two categories: steady state method and non - steady state method[4].The thermal conductivity of the test instrument DRE-III transient heat conduction coefficient is provided by Hunan Xiangtan Xiangyi Apparatus Co. Ltd., the thickness of the sample is $20 \mathrm{~mm}$, the temperature of laboratory is $15^{\circ} \mathrm{C}$, and the relative humidity is $75 \%$.In the experiment, Firstly, $\mathrm{SiO}_{2}$ fiber membrane is dried and weighed and then we measure its thermal conductivity, $\mathrm{SiO}_{2}$ fiber membrane is continuously humidified with humidifier and its thermal conductivity is measured many times. The specific test method of thermal conductivity is as follows:

1. Put the probe into two sample planes that need to measure thermal performance and firmly fix the probe and sample on the test bench.

2. The bridge is balanced before the experiment, if the resistance of one sensor is 1 to $50 \mathrm{Ohm}$, the current should not exceed $1 \mathrm{~mA}$.

3. The output power and measurement time are set, and the lower power is preferred to heat the probe and to record the voltage increment and temperature rise during the measurement.

4. At least 100 time points should be collected during the measurement time.

5. According to figure 1, the following formula is used to calculate the temperature rise $\Delta \mathrm{T}(\mathrm{t})$ of the probe and the read out voltage $\Delta \mathrm{U}(\mathrm{t})$ after recording the time and voltage data, the temperature rise of the probe is calculated by formula (1): 


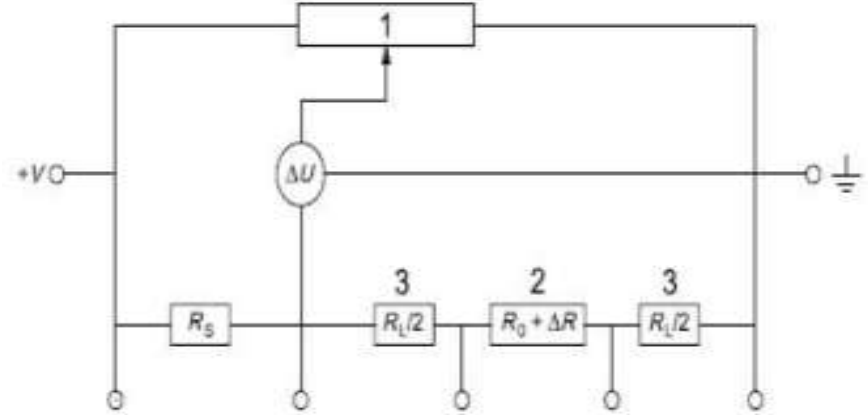

Fig 1: A schematic diagram of electric bridge with increase in the resistance value of the probe

1 - Potentiometer; 2 - Probe;

3 - Probe lead line; $\quad \mathrm{R}_{\mathrm{s}}$ - Series resistance $(\Omega)$;

$\mathrm{R}_{\mathrm{L}}$ - The total resistance of the probe lead $(\Omega)$;

$\mathrm{R}_{0}$ - Resistance of the probe before the transient heating $(\Omega)$;

$\Delta \mathrm{R}$ - The increase of the probe resistance $(\Omega)$;

$\Delta \mathrm{U}$ - The voltage imbalance caused by the increase of the probe resistance $(\mathrm{V})$;

$$
\Delta T(t)=\frac{\left(\mathrm{R}_{\mathrm{S}}+\mathrm{R}_{\mathrm{L}}+\mathrm{R}_{0}\right) \cdot \Delta \mathrm{U}(\mathrm{t})}{\left[\mathrm{J}_{0} \bullet \mathrm{R}_{\mathrm{S}}-\Delta \mathrm{U}(\mathrm{t})\right] \cdot\left(\alpha \cdot \mathrm{R}_{0}\right)}
$$

$\Delta T(t)$ - The average temperature rise of the probe $(K)$;

$\Delta \mathrm{U}(\mathrm{t})$-Unbalanced output of bridge road caused by change of probe resistance $(\mathrm{V})$;

$\alpha$ - The temperature coefficient of the resistance of the probe $\left(1 / \mathrm{K}^{-1}\right)$;

$\mathrm{J}_{0}$-Initial current of sensor during transient process (A);

6. Change the test temperature to cover the temperature required by the sample in order to ensure the temperature balance at each temperature[5].

7. After the test is completed at the highest temperature, it is cooled to one or more lower temperatures to repeat the measurements[6].

8. The thermal conductivity measured under different temperatures and pressures is recorded.

9. Thermal performance calculation:

For a slight rise in the temperature of the probe, there are the following equations:

$$
\begin{array}{r}
\mathrm{R}(\mathrm{T})=\mathrm{R}_{0} \bullet(1+\alpha \cdot \Delta \mathrm{T}(\mathrm{t})) \\
\Delta \mathrm{T}(\mathrm{t})=\mathrm{T}(\mathrm{t})-\mathrm{T}_{0} \\
\Delta \mathrm{T}(\mathrm{t})=\Delta \mathrm{Ti}(\mathrm{t})+\Delta \mathrm{Ts}(\mathrm{t})
\end{array}
$$

$\Delta \operatorname{Ti}(\mathrm{t})$ - Temperature rise of the insulating layer of the probe $(\mathrm{K})$;

$\Delta \mathrm{Ts}(\mathrm{t})$ - Sample surface temperature rise $(\mathrm{K})$;
It is assumed that a double line probe is approximated made up of a number of concentric equidistance circles, and the heat conductivity equation is as follows:

$$
\Delta \mathrm{Ts}(\mathrm{t})=\mathrm{P}_{0}\left(\Pi^{3 / 2} \cdot \mathrm{r} \bullet \lambda\right)^{-1} \mathrm{D}(\tau)
$$

$\mathrm{P}_{0}$ - The output power of the probe;

$r$-The radius of the outer ring of the probe;

$\lambda$ - The thermal conductivity of the sample;

$\tau$ - Characteristic time ratio;

$$
\tau=(\mathrm{t} / \theta)^{1 / 2}
$$

$\theta$ - Characteristic measurement time, $\theta=\mathrm{r}^{2} / \mathrm{K}$

$\mathrm{K}$ - Thermal diffusivity of materials;

$\mathrm{D}(\tau)$ - The dimensionless time function;

$$
\left.\mathrm{D}(\tau)=\cdot[\mathrm{m}(\mathrm{m}+1)]^{-2} \int_{0}^{\tau} \sigma^{-2} \sum_{l=1}^{m} l \sum_{k=1}^{m} k \exp \left\{\frac{-\left(l^{2}+k^{2}\right)}{4 m^{2} \sigma^{2}}\right\} I_{0}\left\{\frac{(l k)}{2 m^{2} \sigma^{2}}\right\}\right] d \sigma
$$

$\mathrm{m}$ - Concentric ring source number;

$\mathrm{I}_{0}$ - Modified Bessel function;

$\mathrm{t}_{\mathrm{c}}$ - Time correction;

$$
\tau_{\mathrm{c}}=\left(\left(\mathrm{t}-\mathrm{t}_{\mathrm{c}}\right) / \theta\right)^{1 / 2}
$$

\subsection{Test Instruments}

The main technical parameters of the DRE-III thermal conductivity tester are detailed in Table 1.

Table 1: The main technical parameters of the DRE-III thermal conductivity tester

\begin{tabular}{|l|l|}
\hline Technical indicators & Parameter \\
\hline Measuring object & $\begin{array}{l}\text { Metals, alloys, ceramics, silicon, } \\
\text { polymers, adhesives, etc. }\end{array}$ \\
\hline Sample size & $\begin{array}{l}\text { A lump or cylinder, requiring } \\
\text { only a relatively smooth surface }\end{array}$ \\
\hline Temperature range & Room temperature to $120^{\circ} \mathrm{C}$ \\
\hline $\begin{array}{l}\text { Precision of temperature } \\
\leq 0.001^{\circ} \mathrm{C}\end{array}$ \\
\hline $\begin{array}{l}\text { Relative error of } \\
\text { measurement }\end{array}$ & $\leq 3 \%$ \\
\hline Repeatability error & $\leq 3 \%$ \\
\hline Power & $30 \mathrm{~V} \mathrm{DC}$ \\
\hline $\begin{array}{l}\text { Range of thermal } \\
\text { conductivity }\end{array}$ & $0.005 \sim 100 \mathrm{~W} /(\mathrm{m} \cdot \mathrm{K})$ \\
\hline Thermal diffusivity & $0.1 \sim 100 \mathrm{~mm} / \mathrm{s}$ \\
\hline
\end{tabular}




\begin{tabular}{|l|l|}
\hline Measurement time & $10 \sim 160 \mathrm{~s}$ \\
\hline External power supply & AC $220 \mathrm{~V} \pm 10 \% ; 50 / 60 \mathrm{~Hz}$ \\
\hline Entire Power & $<500 \mathrm{~W}$ \\
\hline $\begin{array}{l}\text { Equipment reference } \\
\text { standard }\end{array}$ & ISO22007.2-2008 \\
\hline
\end{tabular}

The thermal conductivity test site is shown in Figure 2:

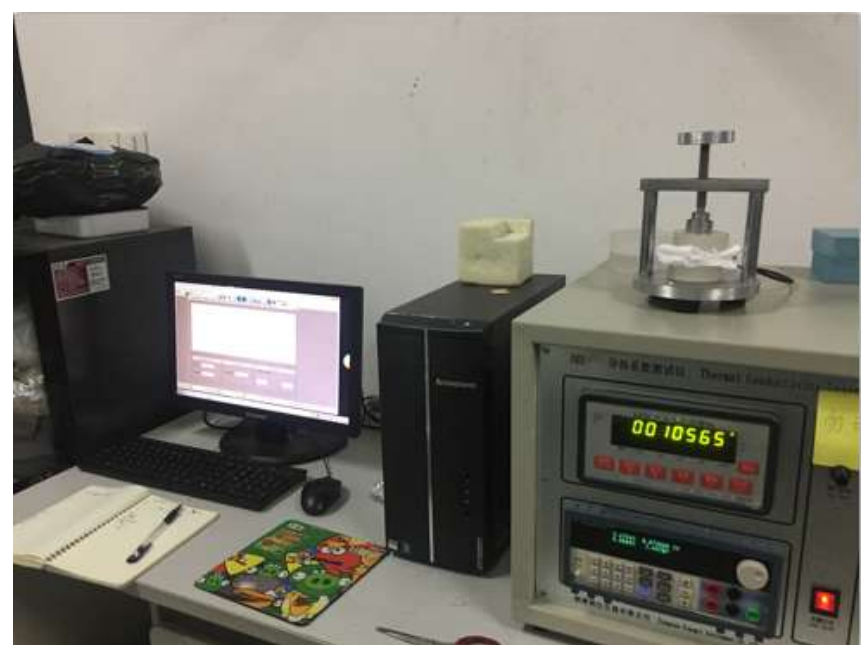

Fig 2: Thermal conductivity test site

\section{RESULTS AND ANALYSIS}

As shown in Figure 3, the $\mathrm{SiO}_{2}$ fiber membrane has a great influence on its thermal conductivity of the film after it is dampened, the thermal conductivity of $\mathrm{SiO}_{2}$ fiber membrane increases slowly with the increase of moisture content first and then increases rapidly, and then tends to be stable and slow. Under the condition of almost no water, the thermal conductivity of $\mathrm{SiO}_{2}$ fiber membrane is the minimum 0.049 $\mathrm{W} /(\mathrm{m} \bullet \mathrm{K})$, When the moisture content of $\mathrm{SiO}_{2}$ fiber membrane is higher than $20 \%$, the thermal conductivity increases rapidly with the increase of moisture content, the maximum thermal conductivity $0.229 \mathrm{~W} /(\mathrm{m} \cdot \mathrm{K})$ occurs when the moisture content of $\mathrm{SiO}_{2}$ fiber membrane is about $46.67 \%$. The thermal conductivity of $\mathrm{SiO}_{2}$ fiber membrane tends to be stable and its value is about $0.2 \mathrm{~W} /(\mathrm{m} \cdot \mathrm{K})$ when its moisture content is between $46.67 \%$ and $100 \%$.Therefore, the $\mathrm{SiO}_{2}$ fiber membrane must pay attention to the waterproof in the heat insulation structure, in order to make the insulation performance of the whole structure better.

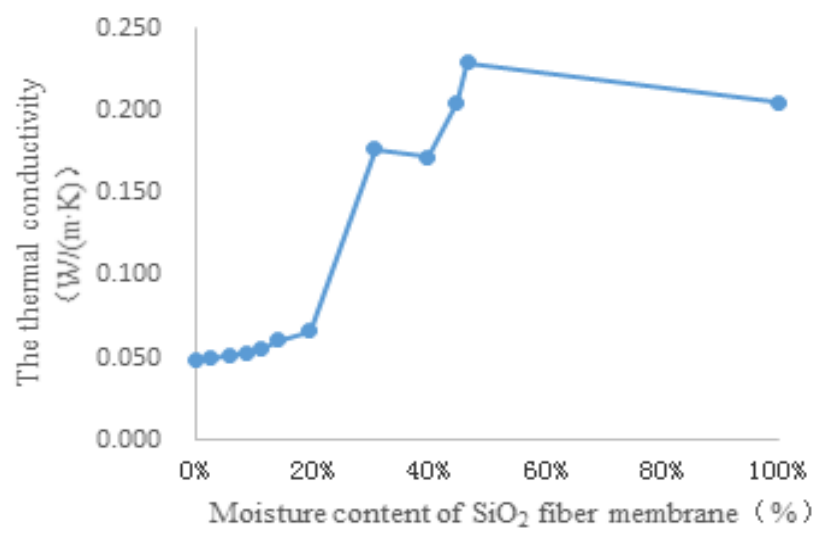

Fig 3: Change of thermal conductivity of $\mathrm{SiO} 2$ fiber film with water content

\section{CONCLUSION}

The thermal conductivity of $\mathrm{SiO}_{2}$ fiber membrane material under different water content is tested. The conclusions are as follows:

(1) The thermal conductivity of $\mathrm{SiO}_{2}$ fiber membrane increases slowly with the increase of moisture content first and then increases rapidly, and then tends to be stable and slow. Thethermal conductivity of $\mathrm{SiO}_{2}$ fiber membrane is between $0.049-0.229 \mathrm{~W} /(\mathrm{m} \cdot \mathrm{K})$.

(2) When the moisture content of $\mathrm{SiO}_{2}$ fiber membrane is higher than $20 \%$, the thermal conductivity increases rapidly with the increase of moisture content, the thermal conductivity of $\mathrm{SiO}_{2}$ fiber membrane tends to be stable when its moisture content is between $46.67 \%$ and $100 \%$.

(3) The water content should not exceed $20 \%$ when the $\mathrm{SiO}_{2}$ fiber membrane is used as a thermal insulation material, and it is better to take waterproof measures in the application.

\section{REFERENCES}

[1]. Chen Yuecheng.Preparation of flexible $\mathrm{SiO}_{2}$ nanofibers and their application in the field of separation[D].Shanghai:Donghua University.2013,12.

[2]. Wang Yongchuan,Zhen Jiao,Fang Jingyu.Experimental study on thermal conductivity of sludge drying process[J]. Solar energy Journal, 2015,36(3):703-707.

[3]. Ma Xiaojing.Experimental and Numerical Study on heat transfer characteristics of aluminum and multi insulation composite plates[D].Lanzhou:Lanzhou Jiaotong University. 2014,4 .

[4]. Chenlan.Ultrathin flexible multilayer composite film and its thermal insulation performance[D]. Shanghai: Donghua University.2007,12.

[5]. Haslinda Mohamed Kamar, Nazri Kamsah, Ahmad Miski Mohammad Nor. Numerical Analysisof Air-Flow and Temperature Field in a Passenger Car Compartment[J]. Applied ThermalEngineering. 2008:1697-1704.

[6]. T. Han. Three-dimensional navier-stokes simulation for passenger compartment cooling [J]. Int.J. Vehicle Des. $1989,10(2) ; 175-186$. 